\title{
Talking about the Main Points of the Layout Design of Industrial Parks in Pharmaceutical Enterprises
}

\author{
China Aviation Planning and Design Institute (Group ) CO. LTD., Beijing 100120, China
}

\section{Introduction}

The pharmaceutical industry is known as never declining sunrise industry, is one of the fastest growing industries in the country and even the world. Statistics show that the past five years, China's pharmaceutical industry, the average annual growth rate of $23 \%$, far more than GDP growth. With the development of the economy, the improvement of people's income level, the enhancement of people's health consciousness, the medical industry ushered in a broader space for development, especially since the establishment of the national health insurance system, the development of the whole market due to the policy faster and faster.

According to the "national competitive advantage theory" point of view, the competitive advantage comes from the industrial agglomeration, and the resulting competitive advantage is difficult to be taken away by other enterprises, is the continued competitiveness. The accumulation of pharmaceutical industry is of great strategic significance to promote the upgrading of industrial competitiveness and realize the sustainable development of industry. Therefore, the construction of pharmaceutical industry park to become the major domestic pharmaceutical business group of the inevitable trend.

\section{Design Technology of GPS Positioning High-rise Building}

\subsection{Background analysis}

In recent years, the distribution of China's pharmaceutical industry cluster has been further developed, has been initially formed to the Yangtze River Delta, the Bohai Sea as the core, the Pearl River Delta, Northeast and other eastern regions of the rapid development of industrial space pattern. With the development of domestic policies and the merger and reorganization of various pharmaceutical companies, the major pharmaceutical groups for the integration of resources, enhance management, build a platform, the construction of pharmaceutical industry park has become an inevitable choice. According to the dominant model is divided into government-led, businessled, school or private non-profit institutions led three models. With the country on the introduction of the relevant policies to promote the pharmaceutical industry and the free flow of capital markets, business-oriented pharmaceutical industrial park construction has become the mainstream of domestic and international markets.

1.2 The characteristics of the pharmaceutical industry park

Pharmaceutical industry park generally has the following characteristics:

(1) The admission of enterprises with different legal representative, complex structure;

(2) The type of enterprise products, many formulations, the difference is greater;
Abstract: This paper analyzes the background and characteristics of the development of industrial parks in pharmaceutical enterprises, and puts forward the main points of the whole process zoning design of the industrial park with the product technology and engineering process as the traction. Combined with the actual project case, the above design points into the actual construction projects, the pharmaceutical industry industrial park of the process design points.

\section{Key words:}

pharmaceutical industry park; cross pollution; unidirectional flow; gravity flow; modularity

Published online: 3th Sept, 2017

(3) The size of the enterprise production enterprises of different sizes;

(4) The existing park enterprises or projects accounted for a smaller proportion of the total size of the future admission products and projects with uncertainty;

(5 ) Industrial park construction to have the majority of incubation function, to provide investment technology platform for investment;

(6) Industrial Park requires 
centralized management, the overall operation.

2. The pharmaceutical industry park overall process zoning design points

In the design of pharmaceutical industrial park, the overall process zoning design is the most important, the overall process zoning to the monomer process design as the basis, and ultimately guide the monomer process design, the monomer process design must meet the overall process zoning concept $^{[1]}$. In the overall process zoning, it is necessary to consider the logical relationship and mutual influence of the process production between the monomer products, but also to meet the requirements of the enterprise management and the requirements of the regulatory authorities. In the pharmaceutical industry park in the overall process zoning should be a good use of the function, process streamline, product type, pollution level, corporate governance structure and other points, in line with the development of the enterprise itself to develop the overall process design concept and implementation plan.

2.1 According to the use of functional design of the overall process zoning

General industrial park construction content, including production plants, office buildings, research and development laboratories, quality inspection center, storehouse, shift dormitory, boiler room, sewage treatment. The overall process zoning should be based on the specific use of functional classification, the functional areas should be relatively concentrated. In accordance with the drug life cycle can be divided into drug research and development, drug production, drug circulation three areas. According to the function can be divided into production areas, research and development office auxiliary area and public works supporting area (Figure 2-1).

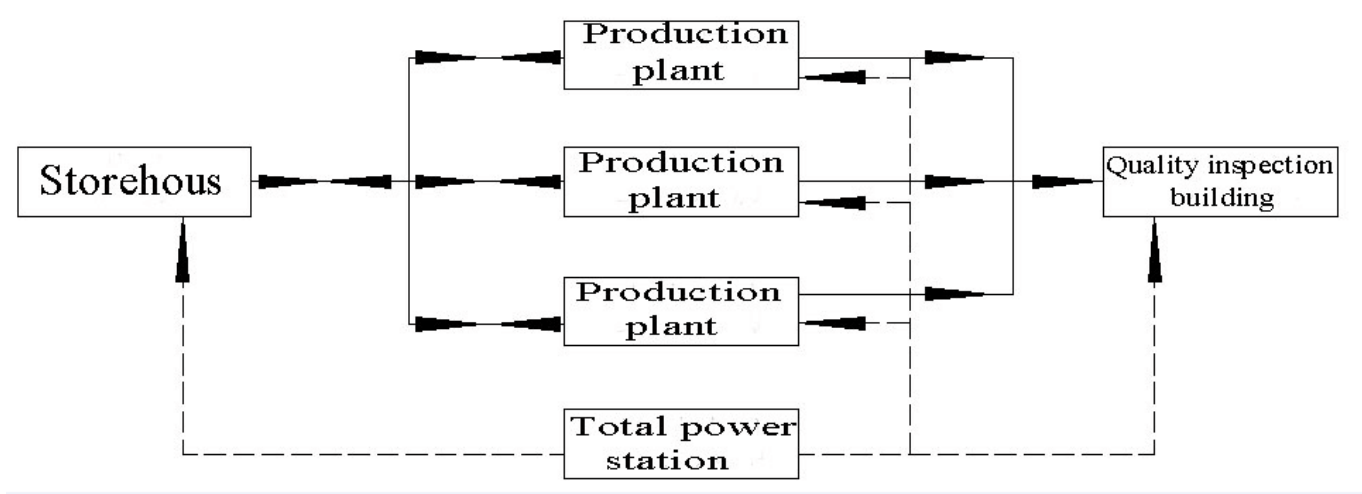

Figure 2-1 Functional diagram of the pharmaceutical industry park

2.2According to the process stream line for the overall process zoning design

The overall process zoning design should be based on the entire drug circulation line for scientific arrangements, the drug production stream stream into the overall process planning design concept.
The entire production process of the drug to the main flow of logistics, the layout of the production units ${ }^{[2]}$, such as: materials into the park, the first storage in the original material library; Subsequently, the material transported by the park transport system to the production workshop. Different production workshop, according to the pharmaceutical production process, but also its order, such as: the first semifinished products production workshop, after sub-packaging workshop. Finally, the finished product is shipped to the finished product store as shown in Figure 22.

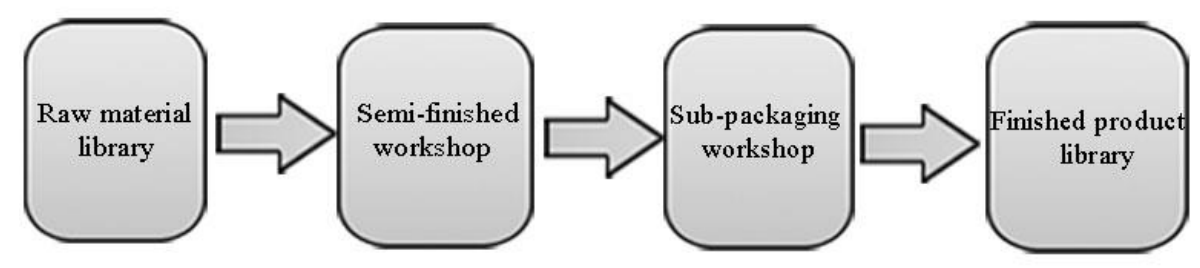

Figure 2-2 Schematic diagram of the process stream 
2.3In accordance with the pollution level of the overall process zoning design $^{[3]}$

According to the pollution level of each functional area within the park, combined with the overall meteorological conditions and municipal conditions in the area where the park is located, the production unit with high risk of pollution and harm should be considered. It needs to be considered away from the main production area, away from the flow of people, Wind direction and other factors. Fully reduce the risk of pollution to the whole park ${ }^{[4]}$.

Pharmaceutical production park pollution units include: dangerous goods store $e^{[5]}$, sewage treatment station, animal room[6] and so on. The design of these production units, in addition to the need to meet the relevant regulatory requirements, but also need to give full consideration to the unit of other production areas, park production staff and the municipal environment and other factors ${ }^{[7]}$, The pollution risk unit is generally set in the relatively independent corner of the plot[8].

2.4 According to the type of product for the overall process zoning design

The main types of pharmaceutical products include: biological products, Chinese medicine, chemical drugs and medical equipment. According to the pharmaceutical formulations are mainly divided into liquid preparations, solid preparations ${ }^{[9]}$. The overall process zoning design, according to the type of enterprise products and formulations of the district, the same type and dosage forms of drugs can be relatively concentrated, the formation of unit groups. From the GMP certification and clean production point of view, biological products take precedence over traditional Chinese medicine and chemical medicine, liquid preparations take precedence over solid preparations.

\subsection{According to the corporate} governance structure of the overall process zoning design

The country's current drug management is based on the legal system of corporate ownership of the drug registration system, a drug must be registered under a corporate company. Some group companies in the construction of pharmaceutical industry park, will be their different corporate enterprises into the park, and for the introduction of other enterprises to provide a platform for admission. Therefore, the overall planning of the park need to take full account of the needs of product certification, according to the enterprise legal person to carry out the overall process zoning design, the formation of different corporate legal division of the principle of the relatively independent of different blocks to facilitate internal management and product certification needs.

\section{The overall process zoning design case analysis}

A group of construction of pharmaceutical industry park, will be a number of its subsidiaries concentrated in the pharmaceutical industry park, and seek international cooperation, the construction of the region as the center, radiation around the international industrial park to meet its strategic development needs.

The design of the pharmaceutical industry park to meet the company's overall strategic objectives - the same company, the same dream. In accordance with the forward-looking, economic and rational design concept, fully consider the future development of scalability, planning and design, the first consideration into the park of different corporate enterprises, the unified corporate production unit is relatively concentrated. At the same time, in order to meet the group of the same company, the same dream of the design concept, the park will be the same type of pharmaceutical production units set the same concentration. To meet the different corporate production management within the same time, starting from the pharmaceutical industry park as a whole, the formation of drug types unit group. 
As for the description of the above three solutions, we find that [Solution 1] and [Solution 3] are more in line with the target of transformation.

The diagram for the transformation of the oil cooling system using the primary air-cooled (enhanced) + secondary water-cooled (circulating) is shown in Figure 1.
The original air-cooled heat exchanger is retained and strengthened with the new circulating water-cooled heat exchanger used in the series. Simultaneously, add the necessary control valve and bypass pipeline through the system, so that the function of the independent control of the air-cooled and water-cooled has been achieved, especially in seasons without high temperatures.
According to operation, stop the operation of the newly added circulating water-cooled heat transferor or the primary air-cooled (enhanced) and operate the original air-cooled heat transfer alone to save water and electricity resources and reduce production costs, which will, to some extent, increase the flexibility and operability for the maintenance and operation of the oil cooling system. ${ }^{9}$

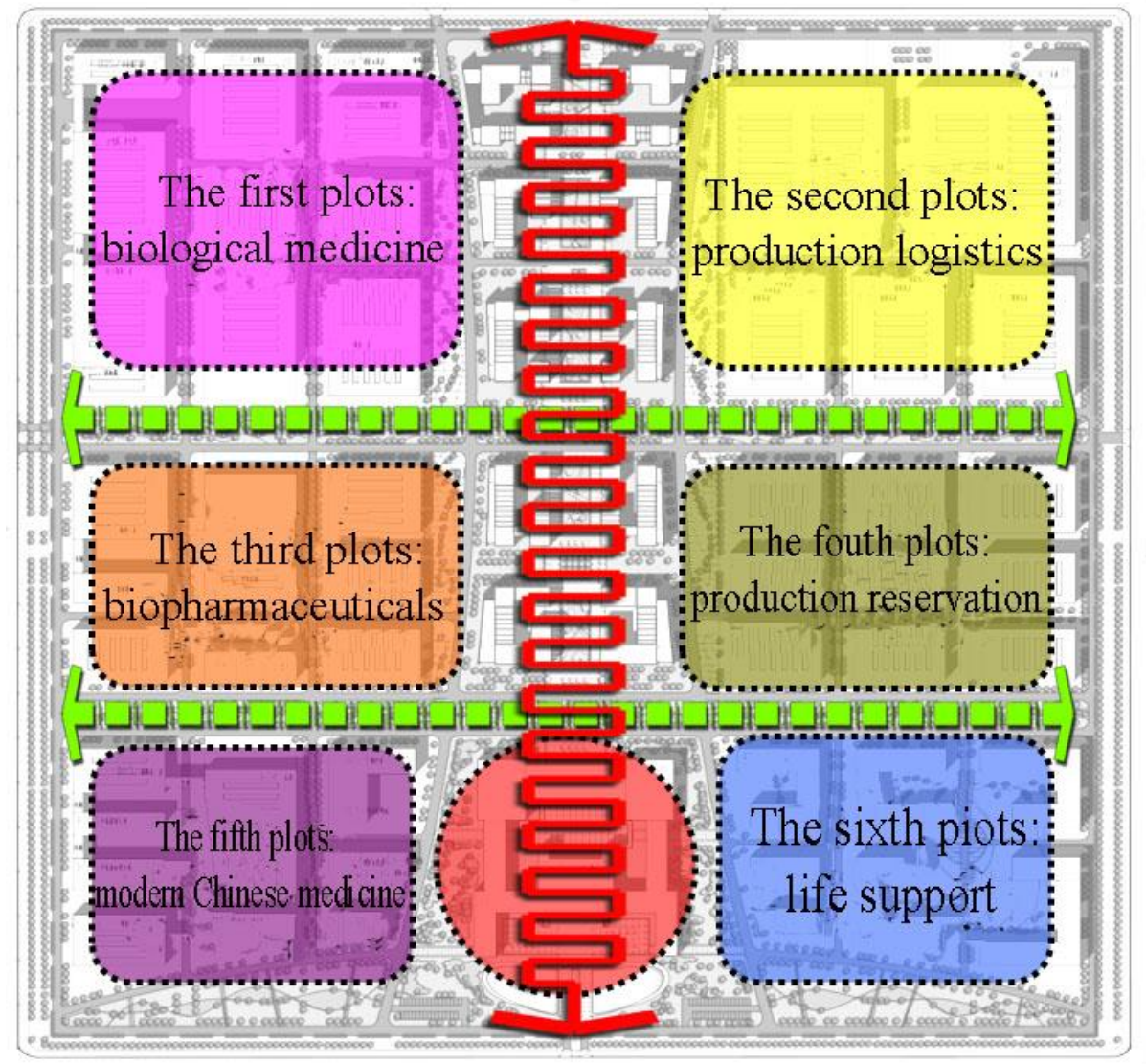

Figure 3-1 The overall process zoning map of the pharmaceutical industry park 
The overall process zoning design, according to the pharmaceutical industry park design points made by the specific requirements, mainly from the following aspects:

1) According to the same company, the same dream of the design concept, in the industrial park in accordance with the use of technology within the function of a park enterprises, admission products for analysis[11]. The public works and production of auxiliary areas set in the central green corridor; R \& D office set in the park on the south side, close to the municipal road.

2) In accordance with the process streamline for zoning, the refrigeration stations and other production units are closely related to the public works station room set in the block of the central side of the green corridor. The storage center will be located in the park next to the main road of the municipal block.

3) When the zoning is carried out according to the pollution level, it is preferable to set the products with higher requirements of the biology and other products in the whole area to the first and third plots; the Chinese medicine and other drugs will be placed in the lower reaches of the whole park; The more risky sewage treatment station is located on the north side of the central auxiliary area.

4) When the product type is divided according to the product type, the liquid preparation products are concentrated in the three plots of the park to form a unified liquid preparation area; the second block is the storage area; the six blocks are the pilot development area; the central plots For the sewage treatment station and other public works station room.

5) In accordance with the corporate governance structure of the division, consider the same enterprise legal person production unit is relatively concentrated in the park to form a centralized management of the group. The north side of the three blocks, the south side were divided

into A, B two companies, so that with a plot, five blocks were formed A, B two companies relatively independent production area. This design to meet the relative concentration of dosage forms at the same time, but also to meet the relatively concentrated corporate design concept.

\section{4. conclusion}

The design of the pharmaceutical industry park must be based on the product production process and engineering process requirements for the overall process and monomer process design relationship, the overall process zoning design must be based on the monomer process design and guide the monomer process design, the overall process division Design should be a comprehensive consideration of the use of technology functions, product categories, process streamline, product and environmental pollution levels, corporate governance structure and other key points to design. To achieve the pharmaceutical industry park within the organic unity of the single building.

\section{References}

[1] Zhao Keke, Sun Wenhao. Planning strategy of biomedical industrial park under the background of "city integration" Taking Wenshan Sanqi Industrial
Park as an example [J]. Small town construction, 2016,07: 80- 85.

[2] "Drug production quality management practices (revised in 2010)"

[3] EU Drug GMP Guide / State Food and Drug Administration Drug Certification Management Center. China Medical Science and Technology Press, 2008.4

[4] Zhang Xiulan, Zhang Heng, Wang Kai, Yang Yixiang, Yang Shouting.Study on the Design Essentials of the Requirement of Non-technology Specialty in the Design of Pharmaceutical Process under the View of "Large Engineering View." Medical Engineering Design, 2010,31 (5)

[5] Wang Jianbo. On safety evaluation and its methods. Forestry labor safety, 2004

[6] GB / T14925 Test animal environment and facilities

[7] Chen Liqun. Pharmaceutical factory design should pay attention to the problem. Pharmaceutical GMP implementation and clean technology compilation

[8] GB 50187-93 for General graphic design specification

[9] Liu with the sea. Based on symbiosis under the idea of high-tech park planning research [D]. Huaqiao University, 2013.

[10] GB 51073-2014 pharmaceutical industry warehousing engineering design specifications

[11] Jing Jun. Taicang City biomedical industry park core supporting area project feasibility study [D]. Donghua University, 2014. 